\title{
RESEARCH ON THE CUTTING PERFORMANCE OF WOOD-PLASTIC COMPOSITE
}

\author{
Zhang Jingzhi' ${ }^{1}, \mathrm{Fu}$ Ling $^{1}$, Ning Tingzhou ${ }^{1^{*}}$ \\ ${ }^{1}$ College of Mechanical and Electrical Engineering, Zaozhuang University, Zaozhuang 277160, Shandong, China \\ Email: ning-tingzhou@163.com
}

\begin{abstract}
In this work, the cutting performance of wood-plastic composite was in focus. To this end, a series of milling experiments were carried out to study the effects of tool rake angle, spindle speed and cutting depth on the cutting forces and surface roughness via orthogonal experimental design. The results obtained are as follows: firstly, the cutting force is negatively related with the increase of rake angle and spindle speed, but has a positive correlation with the increased cutting depth. Then, the surface roughness increases with decreased rake angle and increased cutting depth. However, as spindle speed continuously increases, the surface roughness first declines and then increases. Thirdly, the prominence order of the factors affecting both cutting forces and surface roughness is cutting depth, followed by rake angle and spindle speed. Finally, based on verifying test, the optimum cutting parameters when milling wood-plastic composite with diamond cutters are $15^{\circ}$ front angle, $6000 \mathrm{r} / \mathrm{min}$ spindle speed, $0.5 \mathrm{~mm}$ cutting depth.
\end{abstract}

Keywords: PCD Cutter; WPC; Milling; Cutting Force; Surface Roughness.

\section{Introduction}

Wood-plastic composite (WPC) is mainly made from the mixture of high density polyethylene (HDPE) or polyvinyl chloride (PVC) and wood material, with the addition of auxiliary materials, and then processed by extrusion and molding at a hot-press [1-4]. As a new engineering material, because of its excellent properties, such as moisture-proof, high strength, and green environmental protection, WPC has been widely used in the field of construction, furniture and packaging $[5,6]$.

For the sake of meeting the requirement of different products, WPC will be processed by multiple machining. During the machining, cutting force and surface toughness, as two evaluating parameters, they directly affect the energy consumption and final quality of the product. Thus, cutting force and surface roughness are the emphases for the research of material machining. The effect of cutting parameters on the milling parameters on the cutting forces generated during machining of WPC investigated by Wei et al., they showed that the lower feed rate and cutting depth leads to lower cutting forces [7]. Guo et al. explore the influence of tool geometry and chip thickness on the cutting forces when milling WPC, it was found that chip thickness has the greatest contribution to the cutting forces [8]. In the related research, the cutting force and surface toughness were also studied by Guo et al. during milling of WPC, their work illustrated that the cutting force and surface roughness increased with the increase of average chip thickness and cutting [9].

In actual machining of WPC, the PVC contained in WPC, has great stiffness and strength, which easily causes abnormal tool wear. Therefore, diamond cutting tool is widely used in WPC production and processing because of its superior performance, such as low friction coefficient, low thermal expansion coefficient, high hardness and high elastic modulus [10-13].In the cutting process, the design of tool angle and the selection of cutting parameters not only affect the production energy consumption, but also directly affect the product quality $[14,15]$. However, most WPC processing industries still use the traditional wood cutting technologies, which leads to poor surface quality, low precision and other problems. Therefore, how to scientifically machine WPC and improve its product quality has become an urgent problem for WPC manufacturing industries.

In this work, the effects of tool rake angle, spindle speed and milling depth on cutting force and cutting quality were studied when milling WPC by using diamond cutting tools. By optimizing the cutting parameters, the optimal cutting technology is obtained, which is assumed to provide scientific theory and guidance for WPC production cutting.

\section{Materials and Methods}

Milling was adopted in this work, which was performed on the four-axis machining center. The material properties of WPC and PCD diamond were 
shown in table 1 and table 2 respectively. The rake angle, spindle speed and milling depth were selected as the test factors, and their levels were shown in table 3. In order to better study the influence of various factors on cutting force and cutting quality, the orthogonal experimental table $\operatorname{L9}\left(3^{4}\right)[16,17]$ was adopted. The specific experimental design was shown in table 4.

In this work, the cutting forces and surface roughness of machined surface were measured 3 times in each cutting parameter combination and the average value is taken.

Table 1 Material properties of WPC

\begin{tabular}{|c|c|c|c|c|}
\hline Workpiece & $\begin{array}{c}\text { Elastic } \\
\text { Modulus/GPa }\end{array}$ & $\begin{array}{c}\text { Static bending } \\
\text { intensity/ MPa }\end{array}$ & $\begin{array}{c}\text { Expansion rate of } \\
\text { moisture absorption } \\
\text { thickness/\% }\end{array}$ & $\begin{array}{c}\text { Moisture } \\
\text { content/\% }\end{array}$ \\
\hline WPC & 4.1 & 32.5 & 0.7 & 0.8 \\
\hline
\end{tabular}

Table 2 Geometries and properties of PCD tool

\begin{tabular}{|c|c|c|c|c|c|c|}
\hline \multirow[b]{2}{*}{$\begin{array}{l}\text { PCD } \\
\text { tool }\end{array}$} & \multicolumn{3}{|c|}{ Tool angles } & \multicolumn{3}{|c|}{ Tool properties } \\
\hline & $\begin{array}{c}\text { Rake } \\
\text { angle/ }^{\circ}\end{array}$ & $\begin{array}{l}\text { Wedge } \\
\text { angle }^{\circ}\end{array}$ & $\begin{array}{c}\text { Relief } \\
\text { angle/ }\end{array}$ & $\begin{array}{c}\text { Elastic } \\
\text { Modulus/ GPa }\end{array}$ & $\begin{array}{l}\text { Thermal conductivity/ } \\
\mathrm{W} \cdot \mathrm{m}^{-1} \cdot \mathrm{K}^{-1}\end{array}$ & $\begin{array}{c}\text { Hardness / } \\
\text { HV }\end{array}$ \\
\hline 1 & 5 & 78 & 7 & \multirow{3}{*}{810} & \multirow{3}{*}{550} & \multirow{3}{*}{8000} \\
\hline 2 & 10 & 73 & 7 & & & \\
\hline 3 & 15 & 68 & 7 & & & \\
\hline
\end{tabular}

Table 3 Cutting parameter used in this work

\begin{tabular}{|c|c|c|c|}
\hline \multirow{2}{*}{ Levels } & & Factors & \\
\cline { 2 - 4 } & ${\text { Rake angle }(\mathrm{A}) /^{\circ}}^{\circ}$ & Spindle speed $(\mathrm{B}) / \mathrm{r} / \mathrm{min}$ & Cutting depth $(\mathrm{C}) / \mathrm{mm}$ \\
\hline 1 & 5 & 5000 & 0.5 \\
\hline 2 & 10 & 6000 & 1.0 \\
\hline 3 & 15 & 7000 & 1.5 \\
\hline
\end{tabular}

In this study, the cutting force was measured by Kistler three-direction dynamometer and the data was processed by Dynoware professional software. The cutting component force perpendicular to the tool feed direction is defined as $F_{X}$, and the cutting component force parallel to the tool feed direction is defined as $F_{y}$. In order to better study the changes of cutting forces with different cutting parameters, resultant force was used, which can be obtained based on formula (1) [17].

$$
F_{R}=\sqrt{F_{x}^{2}+F_{y}^{2}}
$$

\section{Results and Discussion}

\subsection{Research on cutting force based on range analysis}

Table 4 shows the range analysis results of cutting force.
According to the comparison of $R_{A}, R_{B}$ and $R_{C}$ values, $R_{C}=155.0>R_{A}=71.0>R_{B}=28.6$, it can be concluded that the $C$ factor has the largest impact on cutting force, followed by the A factor, while the factor B has the least impact on cutting force.

Therefore, during diamond milling of WPC, the prominence order of each factor affecting cutting force is as follows: cutting depth > rake angle > spindle speed.

Cutting force was taken as the evaluation index, according to the data of $\mathrm{K}_{\mathrm{i}}$, the optimal combination of the three factors with the minimum cutting force was selected.

It was concluded that $\mathrm{A}_{3}, \mathrm{~B}_{3}$ and $\mathrm{C}_{1}$ were the optimal cutting parameter combination, e.i., the rake angle of diamond cutting tool was $15^{\circ}$, the spindle speed was $7000 \mathrm{r} / \mathrm{min}$, and the cutting depth was $0.5 \mathrm{~mm}$.

Table 4 Range analysis of cutting force

\begin{tabular}{|c|c|c|c|c|}
\hline Codes & Rake angle $(\mathrm{A}) /^{\circ}$ & Spindle speed $(\mathrm{B}) / \mathrm{r} / \mathrm{min}$ & Cutting depth $(\mathrm{C}) / \mathrm{mm}$ & $\mathrm{F}_{\mathrm{R}} / \mathrm{N}$ \\
\hline 1 & 5 & 5000 & 0.5 & 344 \\
\hline 2 & 5 & 6000 & 1.0 & 381 \\
\hline 3 & 5 & 7000 & 1.5 & 480 \\
\hline 4 & 10 & 5000 & 1.0 & 378 \\
\hline 5 & 10 & 6000 & 1.5 & 460 \\
\hline 6 & 10 & 7000 & 0.5 & 303 \\
\hline 7 & 15 & 5000 & 1.5 & 437 \\
\hline
\end{tabular}




\begin{tabular}{|c|c|c|c|c|}
\hline 8 & 15 & 6000 & 0.5 & 265 \\
\hline 9 & 15 & 7000 & 1.0 & 290 \\
\hline $\mathrm{K}_{1}$ & 401.7 & 386.3 & 304.0 & \\
\hline $\mathrm{K}_{2}$ & 380.3 & 368.7 & 349.7 & \\
\hline $\mathrm{K}_{3}$ & 330.7 & 357.7 & 459.0 & \\
\hline $\mathrm{R}$ & 71.0 & 28.6 & 155.0 & \\
\hline
\end{tabular}

Note: $K_{i}$ in the table represents the mean value of the i level data of each factor, and $R$ represents the difference between the maximum and minimum values of $K_{i}$ for each factor, namely the range of $K_{i}$.

According to the effect of tool angle and cutting parameters on cutting force (figure 1), it can be found that the cutting force decreases with the increase of rake angle, decreases with the increase of spindle speed, and increases with the increase of milling depth. With the increase of rake angle, the cutting edge is easier to remove chips from the cutting layer, so the chip deformation rate decreases, the resistance acting on cutting edge decreases. Therefore, the cutting force decreases with the increase of rake angle. According to the expressions (2) and (3) of feed pet tooth and average cutting thickness, it can be found that feed pet tooth and average cutting thickness decrease with the increase of spindle speed, i.e., the processing amount per unit time becomes smaller, so the cutting force decreases.
On the contrary, the feed pet tooth and average cutting thickness increase with cutting depth increases, i.e., the processing amount per tooth of the tool increases, which increases the tool's loads. Therefore, the cutting force decreases with the increase of spindle speed and with the increase of milling depth.

$$
U_{Z}=\frac{1000 U}{n \cdot z}
$$

Where, $U_{z}$ is feed per tooth, $\mathrm{U}$ is feed speed, and $\mathrm{n}$ is spindle speed.

$$
a_{a v}=U_{z} \cdot \sqrt{\frac{h}{\mathrm{D}}}
$$

Where, $\mathrm{a}_{\mathrm{av}}$ is the average cutting thickness, $\mathrm{h}$ is the milling depth, and $\mathrm{D}$ is the tool radius.
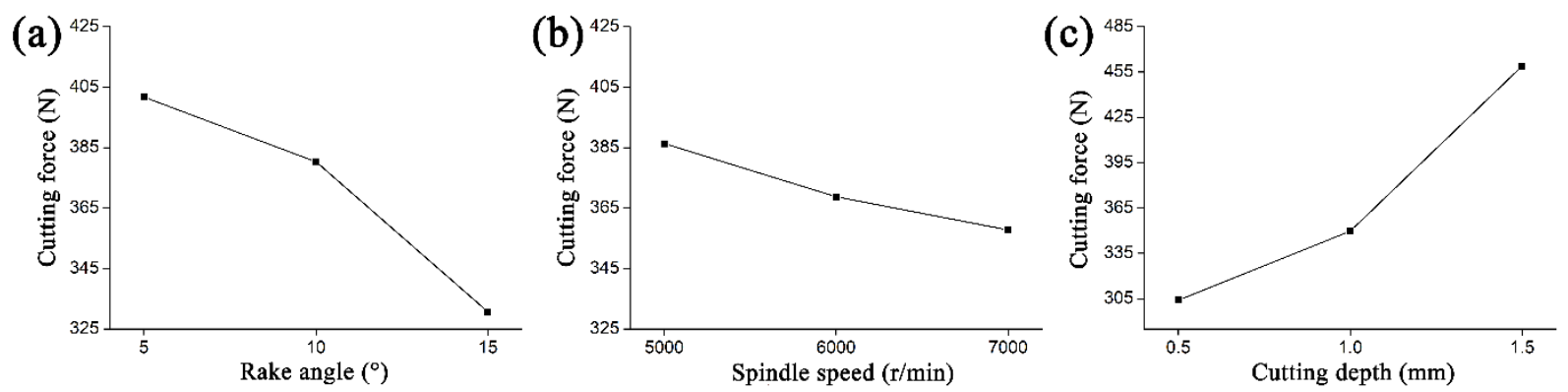

Figure 1: Effect of (a) rake angle, (b) spindle speed and (c) cutting depth on cutting force

\subsection{Research on cutting force based on variance analysis}

Table 5 shows the variance analysis results of cutting force. It can be seen from table 5, $F_{0.05}=19.00<F_{A}=45.5<F_{0.01}=99.00$, therefore, the rake angle has significant influence on cutting force. Similarly, $F_{B}=7.2<F_{0.1}=9.00$, the influence of spindle speed on cutting force is insignificant. And $\mathrm{F}_{0.01}=99.00<\mathrm{F}_{\mathrm{C}}=217.6$, it indicates that the cutting depth has y significant influence on cutting force.

Table 5 Variance analysis of cutting force

\begin{tabular}{|c|c|c|c|c|}
\hline Factor & $\begin{array}{c}\text { Sum of } \\
\text { square }\end{array}$ & $\begin{array}{c}\text { Degree of } \\
\text { freedom }\end{array}$ & F ratio & Significance \\
\hline Rake angle (A) & 7962.9 & 2 & 45.5 & $*$ \\
\hline Spindle speed (B) & 1254.9 & 2 & 7.2 & $/$ \\
\hline Cutting depth (C) & 38064.2 & 2 & 217.6 & $*$ \\
\hline Error & 174.9 & 2 & & \\
\hline Total & 47456.9 & 8 & & \\
\hline
\end{tabular}

Note: if $F<F_{0.1}$, the factor is significant, marked as ${ }^{*}$, if $F<F_{0.1}$, the factor is in significant, marked as $/ .\left(F_{0.1}=9.00\right.$, $F_{0.05}=19.00, F_{0.01}=99.00$.) 


\subsection{Research on surface roughness based on range analysis}

Table 6 shows the range analysis results of the processed surface roughness. By comparing the values of $R_{A}, R_{B}$ and $R_{C}$, it is found that $R_{C}=0.814>R_{A}=0.562>R_{B}=0.083$. Therefore, $C$ factor has the largest impact on the surface roughness, followed by A factor, and factor B has the least impact on surface roughness. Therefore, when diamond tool mills WPC, the significant order of each factor affecting surface roughness is as follows: cutting depth $>$ rake angle $>$ spindle speed.

The surface roughness was taken as the evaluation index, according to the data of $\mathrm{K}_{\mathrm{i}}$, the optimal combination of the three factors with the minimum surface roughness was selected.

It was concluded that $A_{3}, B_{2}$ and $C_{1}$ were the optimal cutting parameter combination, i.e., the rake angle was $15^{\circ}$, the spindle speed was $6000 \mathrm{r} / \mathrm{min}$, and the cutting depth was $0.5 \mathrm{~mm}$.

Table 6 Range analysis of surface roughness

\begin{tabular}{|c|c|c|c|c|}
\hline Codes & Rake angle $(\mathrm{A}) /^{\circ}$ & $\begin{array}{c}\text { Spindle speed } \\
(\mathrm{B}) / \mathrm{r} / \mathrm{min}\end{array}$ & $\begin{array}{c}\text { Cutting depth } \\
(\mathrm{C}) / \mathrm{mm}\end{array}$ & $\mathrm{Ra} / \mu \mathrm{m}$ \\
\hline 1 & 5 & 5000 & 0.5 & 2.0086 \\
\hline 2 & 5 & 6000 & 1.0 & 2.2589 \\
\hline 3 & 5 & 7000 & 1.5 & 3.0522 \\
\hline 4 & 10 & 5000 & 1.0 & 2.2340 \\
\hline 5 & 10 & 6000 & 1.5 & 2.4997 \\
\hline 6 & 10 & 7000 & 0.5 & 1.8698 \\
\hline 7 & 15 & 5000 & 1.5 & 2.3733 \\
\hline 8 & 15 & 6000 & 0.5 & 1.6065 \\
\hline 9 & 15 & 7000 & 1.0 & 1.6531 \\
\hline $\mathrm{K}_{1}$ & 2.440 & 2.205 & 1.828 & \\
\hline $\mathrm{K}_{2}$ & 2.201 & 2.122 & 2.049 & \\
\hline $\mathrm{K}_{3}$ & 1.878 & 2.192 & 2.642 & \\
\hline $\mathrm{R}$ & 0.562 & 0.083 & 0.814 & \\
\hline
\end{tabular}

Note: $K_{i}$ in the table represents the mean value of the i level data of each factor, and $R$ represents the difference between the maximum and minimum values of $K_{i}$ for each factor, namely the range of $K_{i}$.

Figure 2 shows the three-dimensional topography of the processed surface under different cutting parameters. It can be seen from the figure that the different damage was observed on the machined surface under different cutting conditions. Among them, when the rake angle is $5^{\circ}$, the spindle speed is $7000 \mathrm{r} / \mathrm{min}$, and the cutting depth is $1.5 \mathrm{~mm}$, the processed surface (figure 2c) appears many uneven scratches and cutting pits, which seriously affect the surface quality. When the tool rake angle is $15^{\circ}$, the spindle speed is $6000 \mathrm{r} / \mathrm{min}$ and the cutting depth is $0.5 \mathrm{~mm}$, the processed surface (figure $2 \mathrm{~h}$ ) is very smooth with no obvious damage pits. (a),

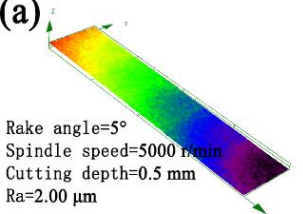

(d)

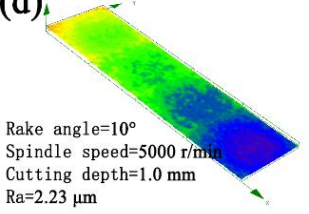

(g),

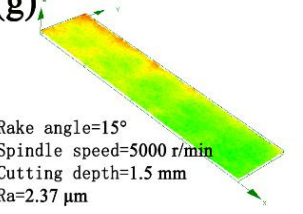

(b)

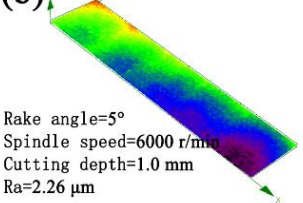

(e)

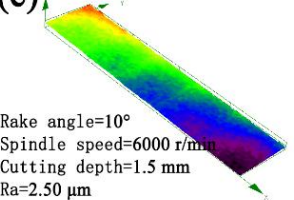

(h)

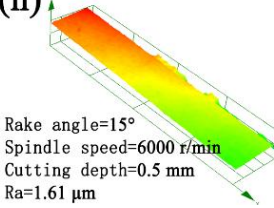

$(\mathrm{c})$

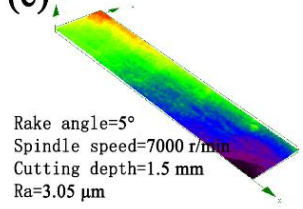

(f)

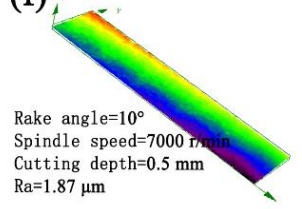

(i),

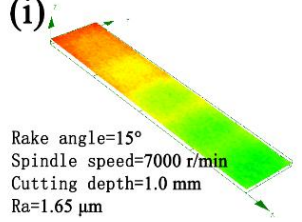

Figure 2: Three-dimensional topography of processed surface 
In order to further study the effect of various parameters on the cutting quality, the effect of tool angle and cutting parameters on the surface roughness was analyzed. It can be found in figure 3 that the roughness of the processed surface decreases with the increase of the rake angle, first decreases and then increases with the increase of spindle speed, and increases significantly with the increase of milling depth. This is because the cutting resistance decreases with the increase of the rake angle, and chips are more easily removed from the cutting layer. Therefore, the quality of the processed surface decreases with the increase of the rake angle. According to the above expressions of feed per tooth and average cutting thickness (2) and (3), it can be found that feed engagement and average cutting thickness decrease with the increase of spindle speed, that is, the processing amount per unit time decreases, so the cutting resistance decreases, the cutting stability improves, and the roughness of the processed surface decreases. With the continuous increase of spindle speed, the friction frequency between the tool and the machined surface increases, and a large amount of cutting heat is generated in the cutting area, PVC contained in WPC decomposes easily in such high cutting temperature, which leads to poorer surface roughness [17].

Therefore, the surface roughness first decreases and then increases with the increase of spindle speed. As the cutting depth increases, the feed per tooth and the average cutting thickness increase, i.e., the processing amount per tooth of the tool increases, which increases the cutting load and reduces the tool stability, so the surface roughness decreases with the increase of milling depth.
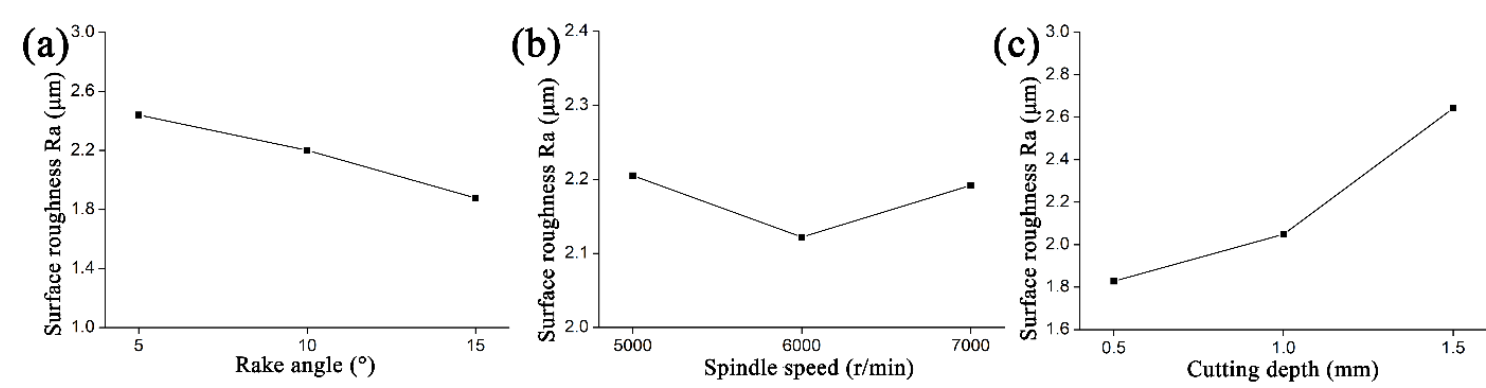

Figure 3: Effect of (a) rake angle, (b) spindle speed and (c) cutting depth on surface roughness

\subsection{Research on surface roughness based on variance analysis}

Table 7 shows the variance analysis results of surface roughness. It can be seen from table 7 , $\mathrm{F}_{\mathrm{A}}=5.371<\mathrm{F}_{0.1}=9.00$, therefore, the influence of rake angle on surface roughness is not significant.
Similarly, $F_{B}=0.135<F_{0.1}=9.00$, the influence of spindle speed on surface roughness is also insignificant.

Meanwhile, $\quad \mathrm{F}_{0.1}=9.00<\mathrm{F}_{\mathrm{C}}=11.933<\mathrm{F}_{0.05}=19.00$ indicates that the cutting depth has a significant influence on surface roughness.

Table 7 Variance analysis of surface roughness

\begin{tabular}{|c|c|c|c|c|}
\hline Factor & $\begin{array}{c}\text { Sum of } \\
\text { square }\end{array}$ & $\begin{array}{c}\text { Degree of } \\
\text { freedom }\end{array}$ & F ratio & Significance \\
\hline Rake angle (A) & 0.478 & 2 & 5.371 & $/$ \\
\hline Spindle speed (B) & 0.012 & 2 & 0.135 & $/$ \\
\hline Cutting depth (C) & 1.062 & 2 & 11.933 & \\
\hline Error & 0.09 & 2 & & \\
\hline Total & 1.642 & 8 & & \\
\hline
\end{tabular}

Note: if $F<F_{0.1}$, the factor is significant, marked as ${ }^{*}$, if $F<F_{0.1}$, the factor is in significant, marked as $/ .\left(F_{0.1}=9.00\right.$, $F_{0.05}=19.00, F_{0.01}=99.00$.)

\subsection{Test optimization and verification}

According to above range analyses, when cutting force and surface roughness were taken as the optimal targets, the optimal cutting parameter combinations were $15^{\circ}$ rake angle, $7000 \mathrm{r} / \mathrm{min}$ spindle speed, $0.5 \mathrm{~mm}$ cutting depth, and $15^{\circ}$ rake angle, $6000 \mathrm{r} / \mathrm{min}$ spindle speed, $0.5 \mathrm{~mm}$ cutting depth. Based on the variance analyses, spindle speed had no significant effect on cutting force and surface roughness, therefore, spindle speed could be appropriately lower to reduce the energy consumption of the machine and improve the tool life. Thus, the optimal cutting parameters can be selected as $15^{\circ}$ tool rake angle, $5000 \mathrm{r} / \mathrm{min}$ spindle speed, and $0.5 \mathrm{~mm}$ cutting depth.

Based on the test verification (table 8), it was found that when the tool rake angle was $15^{\circ}$, the 
spindle speed was $6000 \mathrm{r} / \mathrm{min}$, the cutting depth was $0.5 \mathrm{~mm}$, the cutting force was $265 \mathrm{~N}$, and when the tool rake angle was $15^{\circ}$, the spindle speed was $7000 \mathrm{r} / \mathrm{min}$, the cutting depth was $0.5 \mathrm{~mm}$, the cutting force was $259 \mathrm{~N}$.

Compared with the control group, the cutting force was increased in $8.4 \%$. Figure 4 shows the three-dimensional topography of the processed surface during verification and control tests. As can be seen from the figure, when the tool rake angle was $15^{\circ}$, the spindle speed was $6000 \mathrm{r} / \mathrm{min}$, the cutting depth was $0.5 \mathrm{~mm}$, the surface roughness was $1.6065 \mu \mathrm{m}$, and when the tool rake angle was $15^{\circ}$, the spindle speed was $7000 \mathrm{r} / \mathrm{min}$, the cutting depth was $0.5 \mathrm{~mm}$, the surface roughness was $1.6244 \mu \mathrm{m}$.

Compared with the control group, the surface roughness was slightly reduced in $1.1 \%$.
By further observing their three-dimensional topographies, it was verified that the cutting surface of the verification group was slightly smoother than that of the control group, i.e., the surface quality became better. Therefore, considering the energy consumption of machine, tool life and product quality, the optimal cutting condition for milling WPC by diamond tool were $15^{\circ}$ rake angle, $6000 \mathrm{r} / \mathrm{min}$ spindle speed and $0.5 \mathrm{~mm}$ cutting depth.

In this work, only the cutting force and surface roughness are investigated. However, during the industrial processing of WPC, tool wear has great influence on the machining efficiency and product benefit, it is mainly affected by the cutting parameters and tool geometry. Therefore, the effect of cutting parameters and tool geometry should be focused, thereby supporting comprehensive guidance for WPC machining.

\begin{tabular}{|c|c|c|c|c|c|}
\hline Test & Rake angle/ $^{\circ}$ & $\begin{array}{c}\text { Spindle } \\
\text { speed/r/min }\end{array}$ & $\begin{array}{c}\text { Cutting } \\
\text { depth/mm }\end{array}$ & $\begin{array}{c}\text { Cutting } \\
\text { force } / \mathrm{N}\end{array}$ & $\begin{array}{c}\text { Surface } \\
\text { roughness } / \mu \mathrm{m}\end{array}$ \\
\hline 1 & 15 & 6000 & 0.5 & 265 & 1.6065 \\
\hline 2 & 15 & 7000 & 0.5 & 259 & 1.6244 \\
\hline
\end{tabular}

Note: 1 is the verification group, 2 is the control group.

(a)

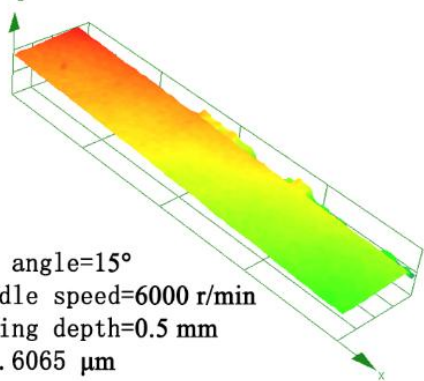

(b)

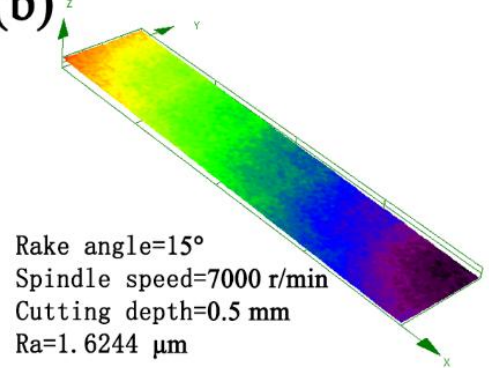

Figure 4: Three-dimensional topography of processed surface during (a) verification and (b) control test

\section{Conclusions}

In this work, the cutting force and surface roughness was studied based on the orthogonal experimental design during WPC milling by using diamond cutter, the main conclusions are as follows:

(1) Cutting force decreases with the increase of rake angle and spindle speed, but increases with the increase of milling depth. The prominence orders each factor affecting cutting force is as follows: cutting depth $>$ rake angle $>$ spindle speed. Meanwhile, both rake angle and milling depth have significant influence on cutting force.

(2) The surface roughness decreases with the increase of the rake angle, while first decreases and then increases with the increase of the spindle speed, and increases with the increase of the cutting depth. The prominence orders each factor affecting the surface roughness is as follows: cutting depth > rake angle $>$ spindle speed, and only the cutting depth has a significant influence on the surface roughness.

(3) It's verified by tests that the optimal cutting parameters of wood-plastic composite milling by diamond tool is $15^{\circ}$ rake angle, the spindle speed is $6000 \mathrm{r} / \mathrm{min}$, and the cutting depth is $0.5 \mathrm{~mm}$.

(4) Tool wear in WPC machining is still an urgent problem, which directly affect the cutting efficiency and benefit. Thus, tool wear should be in focus in the future research.

\section{Acknowledgments}

This work was supported by Zaozhuang Science and Technology Plan Project (2019GX10) and Zaozhuang University Doctoral Research Startup Fund Project (2018BS030). 


\section{References}

[1] Yong, Guo, Shiliu, et al. Thermal Properties of Wood-Plastic Composites with Different Compositions. Materials (Basel, Switzerland), 2019. 681.

[2] Levitas, Valery I, and A. M. Roy. "Multiphase phase field theory for temperature-induced phase transformations: Formulation and application to interfacial phases". Acta Materialia 105(2016):244-257.

[3] Lei W, Ding X Y, Xu C. Effect of Compatibilizing Agent on Mechanical and Thermal Properties of Wood-Plastic Composites. Advanced Materials Research, 2010, 150-151:406-409.

[4] Levitas, Valery I, and A. M. Roy. "Multiphase phase field theory for temperature-and stressinduced phase transformations." Physical Review B 91.174109(2015):7.

[5] Nourbakhsh A, Ashori A. Preparation and Properties of Wood Plastic Composites Made of Recycled High-density Polyethylene [J]. Journal of Composite Materials, 2009, 43(8):877-883.

[6] Wei S Y, Cai Y Y, Yang L, et al. Decoration Technology with the Water Transfer Printing for Polyethylene Wood Plastic Composite Material [J]. Journal of Northeast Forestry University, 2017, 45(8):82-86.

[7] Wei, W., Li, Y., Xue, T., Liu, X., Chen, L., Wang, J., Wang, T., and Cai, Y. (2019). "Research on milling forces during high-speed milling of wood-plastic composites," Bioresources. 14(1), 769-779.

[8] Guo XL, Li RR, Cao PX, et al. (2015) Effect of average chip thickness and cutting speed on cutting forces and surface roughness during peripheral up milling of wood flour/polyvinyl chloride composite Wood research 60(1):147156
[9] Guo, XL, Ekevad, M, Marklund, B, et al. (2014). Cutting forces and chip morphology during wood plastic composites orthogonal cutting. Bioresources. 15(1), 453-461.

[10] Yu Q X, Zhu Z F. History Progress and Prospect of Cutting Tool Materials. Journal of Mechanical Engineering, 2003, 39(12): 62-66.

[11] Zong W J, Li D, Wang H X, et al. On Development of Diamond Tool Technology. China Mechanical Engineering, 2003, 14(13):1165-1169.

[12] Tanaka H, Shimada S, Ikawa N, et al. Wear Mechanism of Diamond Cutting Tool in Machining of Steel. Key Engineering Materials, 2001, 196(8):69-78.

[13] Li Z J, Fang F Z, Gong H, et al. Review of diamond-cutting ferrous metals. The International Journal of Advanced Manufacturing Technology, 2013, 68(5-8):1717-1731.

[14] Zhang Z K, Peng X R, Li W G, et al. Influence of Cutting Direction on Cutting Forces in Wood. China Wood Industry, 2011, 25(6):7-9.

[15] Li B L, Liu X H, Gao Z Y. Experiment and Analysis on the Cutting Force that Influence by Cutting Parameters. Equipment Manufacturing Technology, 2007(4):1-2.

[16] Cui Y, Chang J M, Wang W L. Synthesis process of bio-oil phenolic resin used for glass-fiber reinforced plastic. Journal of Forestry Engineering, 2017, 2(6):67-73.

[17] Wang S T, Hou L D, Chen T T, et al. Surface modification technology of wood composite floor. Journal of Forestry Engineering, 2016, 1(3):3337.

[18] Zhu Z L, Cao P X, Guo X L, et al. Machinability of Luxury Vinyl Tiles during Plain Milling Using a Helical Cutter. Materials, 2019, 12, 2174. 